\begin{tabular}{|c|l|}
\hline Title & Stabilizing effects of ankle bracing under a combination of inversion and axial compression loading \\
\hline Author(s) & Tohyama, Harukazu; Y asuda, Kazunori; Beynnon, Bruce D.; Renstrom, Per A. \\
\hline Citation & $\begin{array}{l}\text { Knee Surgery, Sports Traumatology, Arthroscopy, 14(4), 373-378 } \\
\text { https:/doi.org/_0.1007/300167-005-0652-7 }\end{array}$ \\
\hline Issue Date & 2006-04 \\
\hline Doc URL & http://hdl.handle.net/2115/8435 \\
\hline Rights & The original publication is available at www.springerlink.com \\
\hline Type & article (author version) \\
\hline File Information & Knee_Surgery_14(4)_373_378.pdf \\
\hline
\end{tabular}

Instructions for use 


\title{
Stabilizing Effects of Ankle Bracing Under a Combination of Inversion and Axial Compression Loading
}

\author{
Harukazu Tohyama, MD, PhD*; Kazunori Yasuda, $M D, P h D^{*}$; Bruce D. Beynnon, $P h D^{* *}$ : \\ and Per A. Renstrom, MD, PhD***
}

From the *Department Sports Medicine and Joint Reconstruction Surgery, Department of Advanced Surgery, Hokkaido University School of Medicine, Sapporo, Japan, the ** Department of Orthopaedics \& Rehabilitation, University of Vermont College of Medicine, Burlington, Vermont, and the $* * *$ Section of Sports Medicine, Department of Surgical Science, Karolinska Institute, Stockholm, Sweden

Address correspondence to: Harukazu Tohyama, MD, Department Sports Medicine and Joint Reconstruction Surgery, Hokkaido University School of Medicine, Kita-15 Nishi-7 Kita-ku, Sapporo 060-8638, Japan.

Tel:+81(Japan)-11-706-7211

Fax:+81(Japan)-11-706-7822

E-mail:tohyama@med.hokudai.ac.jp 


\begin{abstract}
The combined effects of bracing, axial compression and inversion rotation on the ankle-subtalar complexes were evaluated. Ex vivo tests under the load-controlled condition were performed on six cadaver ankle specimens using a six degree-of-freedom fixture. Inversion rotation was measured while subjecting the ankle-subtalar complex to a $2.5 \mathrm{~N}-\mathrm{m}$ inversion moment and a combination of the testing variables (brace type, no brace, $178 \mathrm{~N}$ axial compression load, no compression load, $0^{\circ}$ and $20^{\circ}$ of plantar flexion) for a total of 16 tests per specimen. Three commercially available braces (two semirigid types and one lace up type) were evaluated. An axial compression load significantly decreased ankle-subtalar motion in unbraced ankles for the tested inversion moment. The contribution of bracing to stabilization of the ankle was smaller in the axial loading condition than in the no axial loading condition. The semirigid braces had greater stabilizing effects in response to the inversion moment than the lace up brace. Stabilizing effects of bracing were significantly greater in $20^{\circ}$ of plantar flexion than in $0^{\circ}$ of plantar flexion. The most common mechanism for an ankle sprain injury is inversion rotation on a weight-bearing ankle. Therefore, we should not overestimate stabilizing effects of bracing from evaluations of bracing without axial compression loading.
\end{abstract}

Key Words: Ankle, Biomechanics, Brace, Inversion injury, Sprain 
The lateral ligament complex of the ankle is the most frequently injured structure in the physically active population [7, 13]. Therefore, ankle sprains are one of the most common injuries treated by physicians, physical therapists, and athletic trainers. In addition, ankle sprains account for 10 to $20 \%$ of time lost from athletic participation [7]. Traditionally, tape has been the ankle prophylaxis of choice. However, physicians and trainers have turned to removable braces as an alternative for ankle injury prevention along with concurrent improvements in ankle brace design [8, 21]. Because there are the following advantages in ankle bracing. Braces can be applied by the athlete, whereas tape must be applied by a trainer or coach. The brace is easily retightened during use, as opposed to tape, which must be removed and replaced to restore its effectiveness. In light of these factors, braces can be expected to maintain their effectiveness during the entire period of use. On the other hand, several studies have demonstrated that the effectiveness of ankle taping decreases rapidly with exercise [3, 6, 9, 15, 20]. Additionally, braces are a much less expensive application because they can be reused.

A number of studies were conducted to evaluate the biomechanical effects of ankle bracing on an inversion injury $[3,10,11,16,17,22]$. The most common mechanism for an ankle sprain injury is inversion rotation on a weight-bearing ankle [7]. Therefore, several investigators have investigated ankle inversion and bracing under weight bearing conditions in vivo $[1,2,18]$. For 
example, Anderson et al concluded that a external rigid orthosis reduced inversion angle and velocity when an ankle was subjected to a sudden inversion displacement while bearing body weight [1]. Ashton-Miller and Ottaviani concluded that tape or braces in combination with a high top shoe increases baseline resistance to an inversion moment in a weight bearing male [2, 18]. However, none of these studies directly examined the role of axial compression on inversion rotation. No cadaveric biomechanical study has been conducted precisely investigating the stabilizing effects of ankle bracing under axial compression and inversion. The objectives of the present investigation were to; determine what effect an axial compression load has on ankle-subtalar inversion rotation; and compare the stabilizing effects of three different ankle braces during a combination of axial compression and inversion moment loading.

\section{MATERIALS AND METHODS}

\section{Tested Specimen}

Six lower leg specimens from independent donors (five males and a female) were obtained at necropsy and stored at $-20^{\circ} \mathrm{C}$. The mean age of the donor was $57 \pm 17$ years (35 - 89). Prior to testing, each specimen was thawed for 12 hours at room temperature, and the skin, subcutaneous tissues and muscles around the proximal half of the tibia and fibula were removed. The anatomic position of the fibula relative to the tibia was preserved with a bone screw placed 
across the fibula and anchored in the tibia. The tibia and fibula were fixed in a copper cylinder (75 mm diameter) with polymethyacrylate, leaving distal $20 \mathrm{~cm}$ of the tibia and fibula exposed.

\section{Testing Rig}

A six degree-of-freedom testing rig was designed and manufactured to evaluate the stabilizing effect of ankle bracing (Fig. 1). A low top athletic shoe was rigidly secured to the tray (the foot plate) so that a human cadaver specimen in a sock could be placed into the shoe with and without a supportive brace. In this experiment, we used orthogonal coordinates as described below. The dorsi-plantar flexion axis was adjusted to pass through the medial and lateral malleoli [12]. The internal-external rotation axis was adjusted through the tibial shaft which was aligned perpendicular to the MTS table intersecting to the dorsi-plantar flexion axis. The inversion-eversion axis was adjusted perpendicular to the other two axes (Fig. 1). This orthogonal coordinates had an advantage that the inversion-eversion axis was kept at a constant position regardless of the plantar-flexion angle, although this axis was not physiological axis of the subtalar joint. This testing rig allowed only inversion-eversion rotation of the foot plate on which the shoe and the foot were mounted during testing, while any other motions (i.e. plantar flexion, internal-external rotation, and translation motions in the anterior-posterior, the medial-lateral, and proximal-distal directions) were fixed (Fig. 1). The frictionless shaft bearing of the inversion-eversion axis allowed free inversion-eversion motion of the foot plate 
regardless of axial compression loading. On the other hand, the cylinder in which the tibia and fibula were mounted freely moved in the internal-external rotation and translations in the three axes (i.e. the anterior-posterior, the medial-lateral, and proximal-distal translations) by frictionless bearings of the testing rig (Fig. 1). Therefore, this testing rig provided the five-degree of freedom motion of the ankle-subtalar joint complex of the specimen at a given plantar-flexion position. The unrestricted motions in three translational directions minimized forces in response to artificial errors during the setting of the rotational axes. In addition, we confirmed that the artificial moment generated by the rotational displacement of the parts of the testing rig below the inversion axis was negligible. Once the specimen was in the testing rig, the ankle was locked in $0^{\circ}$ or $20^{\circ}$ of plantar flexion. To generate an inversion moment, forces were applied to the round disc which was connected to the shaft of the inversion-eversion rotation by two cables which were attached to the hanging weight and the actuator of MTS Model 810 (Materials Test System, Prairie Eden, MN), respectively. These cables separately ran on the round disc in the two different gutters. The shaft of inversion-eversion was perpendicularly intersected to the round disc at its center. A hanging weight generated an inversion moment of $2.5 \mathrm{~N}-\mathrm{m}$ and the MTS actuator was adjusted to balance a hanging weight. The MTS load cell was zeroed electrically in this condition that the foot table was kept parallel to the MTS table. The MTS actuator then reduced the inversion torque generated by the 
hanging weight for a given magnitude under the MTS load-control mode. The axial compression load was applied using a dead weight. Rotational displacement and inversion moment were determined via the load cell and the linear variable displacement transducer (LVDT) in the MTS. To ensure the accuracy of this determination method of foot inversion angle from the MTS actuator position, we measured the foot inversion angle of the unbraced specimen at $0^{\circ}$ of plantar flexion using the tilt sensor (Micro Strain Inc. Burlington, VT) attached to the specimen's calcaneus. The differences in inversion angle between these two methods were less than $0.23^{\circ}$ in all tests.

\section{Testing Protocol}

Each test consisted of 13 cycles of inversion-eversion moments applied to a maximum of 2.25 $\mathrm{N}$-m using a ramp function with a loading frequency of $0.034 \mathrm{~Hz}$. After ten preconditioning cycles, the subsequent three cycles were found to be repeatable. Therefore, the data analysis was performed on the average of these three inversion cycles. The data were recorded using an analog to digital acquisition system (Techmar, Cleveland, $\mathrm{OH}$ ) at a sampling rate of $5 \mathrm{~Hz}$.

Initially, unbraced specimens were tested unloaded in $0^{\circ}$ and $20^{\circ}$ of plantar flexion, respectively, and then with a $178 \mathrm{~N}$ axial compression load applied to the tibia. Subsequently, the same procedure was used to test three different braces in random order. Two semirigid braces (Sports-Stirrup, Aircast Inc., Summit, NJ and Active Ankle, Biomet Inc., Louisville, KY) 
and one lace-up brace (Ankle Stabilizer, Cramer Product Inc., Gardner, KS) were evaluated. All braces were sized, fitted, and applied by the same investigator (H.T.), as instructed by a representative of the company. For a lace-up brace, each lace was tightened sequentially to 90 N. On the semirigid braces, the hook and loop straps were similarly tightened to $45 \mathrm{~N}$. These initial tensions prevented loosening between the specimen and the brace during testing. However, these tensions may have been tighter than is routinely used.

\section{Statistical Analysis}

The inversion angles at $2.0 \mathrm{~N}$-m of inversion moment were used for all statistical comparison. First, we evaluated the effects of axial compression load and flexion position on unbraced ankles using a two-way analysis of variance (ANOVA) with repeat measures. To evaluate stabilizing effects of ankle bracing, we used the relative inversion rotation after bracing to that before bracing (\% inversion rotation). These data were then analyzed using a three-way ANOVA without repeat measures to determine the effects of brace type, axial compression load, and flexion position on \% inversion rotation. Fisher's PLSD method was used to make post hoc multiple comparisons of the stabilizing effects among three types of brace. Statistical significance was assigned at $\mathrm{p}<0.05$.

\section{RESULTS}


The effects of axial compression on inversion rotation for the unbraced ankle are displayed in Fig.

2. The static compressive load across the ankle significantly decreased the inversion rotation to $36 \%$ and $30 \%$ of the unweighted condition at inversion moment of $2.0 \mathrm{~N}-\mathrm{m}$ in $0^{\circ}$ and $20^{\circ}$ of plantar flexion, respectively $(\mathrm{p}<0.001)$. We could not find significant differences in the inversion rotation values between $0^{\circ}$ and $20^{\circ}$ of plantar flexion $(\mathrm{p}=0.073$, power $=0.425)$.

Regardless of axial compression loading, all kinds of braces significantly reduced the inversion rotation of the ankle at inversion moment of $2.0 \mathrm{~N}-\mathrm{m}$ (Fig. 3) However, the contribution of the brace to the ankle stabilization depended on the type of brace, the axial loading condition, and flexion position of the ankle. Axial compression applied to the ankle significantly increased \% inversion rotation at an inversion moment of $2.0 \mathrm{~N}-\mathrm{m}$, indicating that the contribution of bracing to stabilization of the ankle was smaller in the axial loading condition than in the no axial loading condition (Fig. 4) $(\mathrm{p}<0.001)$. The Aircast and Biomet supports

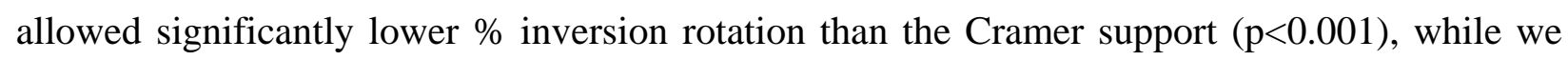
could not find significant differences between the Aircast and Biomet supports $(p=0.844)$. The values of \% inversion rotation in $20^{\circ}$ of plantar flexion were significantly lower than those at $0^{\circ}$ of plantar flexion $(\mathrm{p}<0.006)$.

\section{DISCUSSION}


Ankle-subtalar kinematics can either be examined by the displacement-controlled, or the load-controlled techniques. In the displacement-controlled method, displacement of the joint is controlled and the resulting load and moment are measured, while for the load-controlled approach, loads and moment are controlled with an unconstrained joint and displacement is measured [19]. The load-controlled approach allows tests to be performed under a variety of loading conditions. Therefore, we chose to use the load-controlled condition as we feel it more closely approximates the natural occurring process of ankle injury. The present study had the following limitations. Since this was a cadaveric study, certain factors were not evaluated. The dynamic effects of the stabilizing muscles [1, 14], the subjective comfort of the braces, and the effect of bracing on ankle proprioception [4, 5] were all undetermined. In addition, the specimens used in this study were obtained from relatively old donors. The axial compression load applied in this study was small and static in order to approximate the loading period during the onset of an inversion injury. We applied an axial compression load of $178 \mathrm{~N}$ to the specimens in this study. As a pilot study, we had performed the same testing protocol to this study with an axial compression load of $84 \mathrm{~N}, 178 \mathrm{~N}$ or $356 \mathrm{~N}$. We had not found repeatable moment-displacement curves after ten preconditioning cycles with $356 \mathrm{~N}$ of axial loading, while the subsequent cycles were found to be repeatable after ten preconditioning cycles with an axial compression loading of $84 \mathrm{~N}$ and $178 \mathrm{~N}$. Therefore, there was a high possibility that an axial 
compression load of $356 \mathrm{~N}$ or higher might produce significant creep or fatigue behaviors of the specimens and the testing rig during testing.

This study demonstrated that an axial compression load across the ankle significantly reduces ankle inversion rotation when challenged with an inversion moment using a load-controlled method. Stormont et al. investigated the stabilizing capacity of the ligament and articular surfaces in the ankle during inversion rotation using a displacement-controlled method [23]. They demonstrated that the stabilizing capacity of the articular surface increases from $0 \%$ to $100 \%$ during inversion rotation as the axial compression loading ramped from 0 to $670 \mathrm{~N}$. These findings indicate the articular surfaces play a larger role in ankle stability against inversion rotation with increasing axial compression. Therefore, axial compression loading across the ankle should be account for when investigating inversion rotation of the ankle.

Our data show that the contribution of bracing to stabilization of the ankle is dependent on the axial compression load across the ankle, suggesting that axial compression should be applied in the controlled condition for during the future evaluation of ankle stabilizing devices. The percent reduction of inversion rotation by the ankle braces increased with the application of an axial compression load. This means that the contribution of bracing to stabilization of the ankle was smaller in the axial loading condition than in the no axial loading condition. Previous biomechanical investigations of the stabilizing effects of ankle bracing were performed with no 
axial compression loading $[3,11,16,22]$. Therefore, previous data on the stabilizing effect of ankle bracing may have been overestimated compared to the stabilizing effects of bracing under physiologic loading.

Sprains occur clinically in both dorsiflexion and plantar flexion. In certain situations, only one of the two lateral ligaments is injured. Sprain that preferentially injure the anterior talofibular ligament probably occur in more plantar flexion. This position may be associated with injuries that occur when the player lands on someone else's foot or on uneven ground. With the foot in more plantar flexion, the distance between the ankle and the point of force application (the plantarflexed foot) is greater; therefore, the inversion moment is correspondingly greater. Thus, plantar flexion may be a more vulnerable position for ankle sprains. Our data demonstrate that ankle bracing increases efficacy in plantar flexion.

In conclusion, an axial compression load across the ankle significantly reduces ankle inversion rotation when subjected to an inversion moment. The contribution of bracing to stabilization of the ankle was smaller in the axial loading condition than in the no axial loading condition. Therefore, we should not overestimate stabilizing effects of bracing from evaluations of bracing in response to the inversion moment without axial compression loading. 


\section{ACKNOWLEDGEMENTS}

This study was supported by a grant from the Air Cast Corporation..

\section{REFERENCES}

1. Anderson DL, Sanderson DJ, Henning EM (1995) The role of external nonrigid ankle bracing in limiting ankle inversion. Clin J Sports Med 5: 18-24.

2. Ashton-Miller JA, Ottaviani RA, Hutchinson C, et al (1996) What best protects the inverted weightbearing ankle against further inversion? Evertor muscle strength compares favorably with shoe height, athletic tape and three orthoses. Am J Sports Med 24: 800-809.

3. Bunch RP, Bednarski K, Holland D, et al (1985): Ankle joint support. A comparison of reusable lace-on braces with taping and wrapping. Phys Sports Med 13:59-62.

4. Burks RT, Bean BG, Marcus R, et al (1991) Analysis of athletic performance with prophylactic ankle devices. Am J Sports Med 19: 104-106.

5. Feuerbach JW, Grabiner MD, Koh TJ, et al (1994) Effect of an ankle orthosis and ankle ligament anesthesia on ankle joint proprioception, Am J Sports Med 22: 223-229.

6. Fumich RM, Ellison AE, Guerin GJ. et al (1981) The measured effect of taping on combined foot and ankle motion before and after exercise. Am J Sports Med 9:165-170.

7. Garrick JG (1977) The frequency of injury, mechanism of injury, and epidemiology of ankle 
sprains. Am J Sports Med 5: 241-242.

8. Garrick JG, Requa RK (1973) Role of external support in the prevention of ankle sprain. Med Sci Sports Exerc 5: 200-203.

9. Glick JM, Gordon RB, Nishimoto D (1976) The prevention and treatment of ankle injuries. Am J Sports Med 4: 136-141.

10. Greene TA, Hillman SK (1990) Comparison of support provided by a semirigid orthosis and adhesive ankle taping before, during, and after exercise. Am J Sports Med 18: 498-506.

11. Gross MT, Bradsshaw MK, Ventry LC et al (1987) Comparison of support provided by ankle taping and semirigid orthosis. J Orthop Sports Phys Ther 9: 33-39.

12. Inman, V.T. (1976) The Joints of the Ankle. Williams \& Wilkins, Baltimore.

13. Jackson DW, Ashley RL, Powell JW (1974) Ankle sprains in young athletes. Relation of severity of disability. Clin Orthop 101: 201-215.

14. Karlsson J, Andreasson GO (1992): The effect of external ankle support in chronic lateral ankle joint instability: An electromyographic study. Am J Sports Med 20: 257-261.

15. Laughman RK, Carr TA, Chao EY, et al (1980) Three-dimensional kinematics of the taped ankle before and after exercise. Am J Sports Med 8:425-431.

16. Lofvenberg R, Karrholm J (1993) The influence of an ankle orthosis on the talar and calcaeal motions in chronic lateral instability of the ankle. Am J Sports Med 21: 224-227. 
17. Myburgh KH, Vaughan CL, Isaacs SK (1984) The effects of ankle guards and taping on joint motion before, during, and after a squash match. Am J Sports Med 12: 441-446.

18. Ottaviani RA, Ashton-Miller JA, Kothari KU, Wojtys EM (1995) Basketball shoe height and the maximal muscular resistance to applied ankle inversion and eversion moments. Am J Sports Med 23: 418-423.

19. Panjabi MM (1988) Biomechanical evaluation of spinal fixation devices. I. A conceptual framework. Spine 13: 1129-1134.

20. Rarick GL, Bigley G, Karst R, et al (1962) The measurable support of the ankle joint by conventional methods of taping. J Bone Joint Surg 44A: 1183-1190.

21. Rivere GD, Clarke TJ, Yates CS, et al (1988) Retrospective comparison of taping and ankle stabilizers in preventing ankle injuries. Am J Sports Med 16: 228-233.

22. Shapiro MS, Kabo JM, Mitchell PW, et al (1994) Ankle sprain prophylaxis. An analysis of the stabilizing effects of braces and tape. Am J Sports Med 22:78-82.

23. Stormont DM, Morrey BF, An KN, et al (1985) Stability of loaded ankle. Relation between articular restraint and primary and secondary static restrains. Am J Sports Med 13:295-300. 


\section{FIGURE LEGENDS}

Fig. 1 Schematic of six degree-of-freedom testing apparatus

Fig. 2 Inversion moment versus inversion rotation for unbraced ankles with and without axial compression across the ankle in $0^{\circ}$ (a) and $20^{\circ}$ (b) of plantar flexion. A two-way ANOVA for the effects on the inversion rotation at inversion moment of $2.0 \mathrm{~N}-\mathrm{m}$ showed that there were significant effects of axial compression $(p=0.0001$, power: 1 - $\beta$ $=1.000$ ), while no significant effect of plantar flexion was found $(\mathrm{p}=0.0727$, power: 1 $\beta=0.425)$. No significant interaction was found between axial compression and plantar flexion ( $\mathrm{p}=0.2160$, power: $1-\beta=0.218)$.

Fig. 3 Inversion rotation of the ankles after bracing with and without axial compression across the ankle in $0^{\circ}$ (a) and $20^{\circ}$ (b) of plantar flexion. Regardless of axial compression loading, all kinds of braces significantly reduced the inversion rotation of the ankle at inversion moment of $2.0 \mathrm{~N}-\mathrm{m}\left(\mathrm{p}=0.0001\right.$ for each brace in $0^{\circ}$ and $20^{\circ}$ of plantar flexion).

Fig. 4 Percent inversion rotation of the ankles after bracing with and without axial compression across the ankle in $0^{\circ}$ (a) and $20^{\circ}$ (b) of plantar flexion. Percent inversion means the relative rotation after bracing at inversion moment of $2.0 \mathrm{~N}-\mathrm{m}$ to that before bracing. A three-way ANOVA for the effects on \% inversion rotation 
showed that there were significant effects of axial compression $(p=0.0001$, power: 1 - $\beta$

$=1.000)$, type of brace $(p=0.0001$, power: $1-\beta=1.000)$, and plantar flexion $(p=0.0062$, power: $1-\beta=0.810$ ), while no significant interaction was found among three effects $(p=0.8976$, power: $1-\beta=0.066)$. 


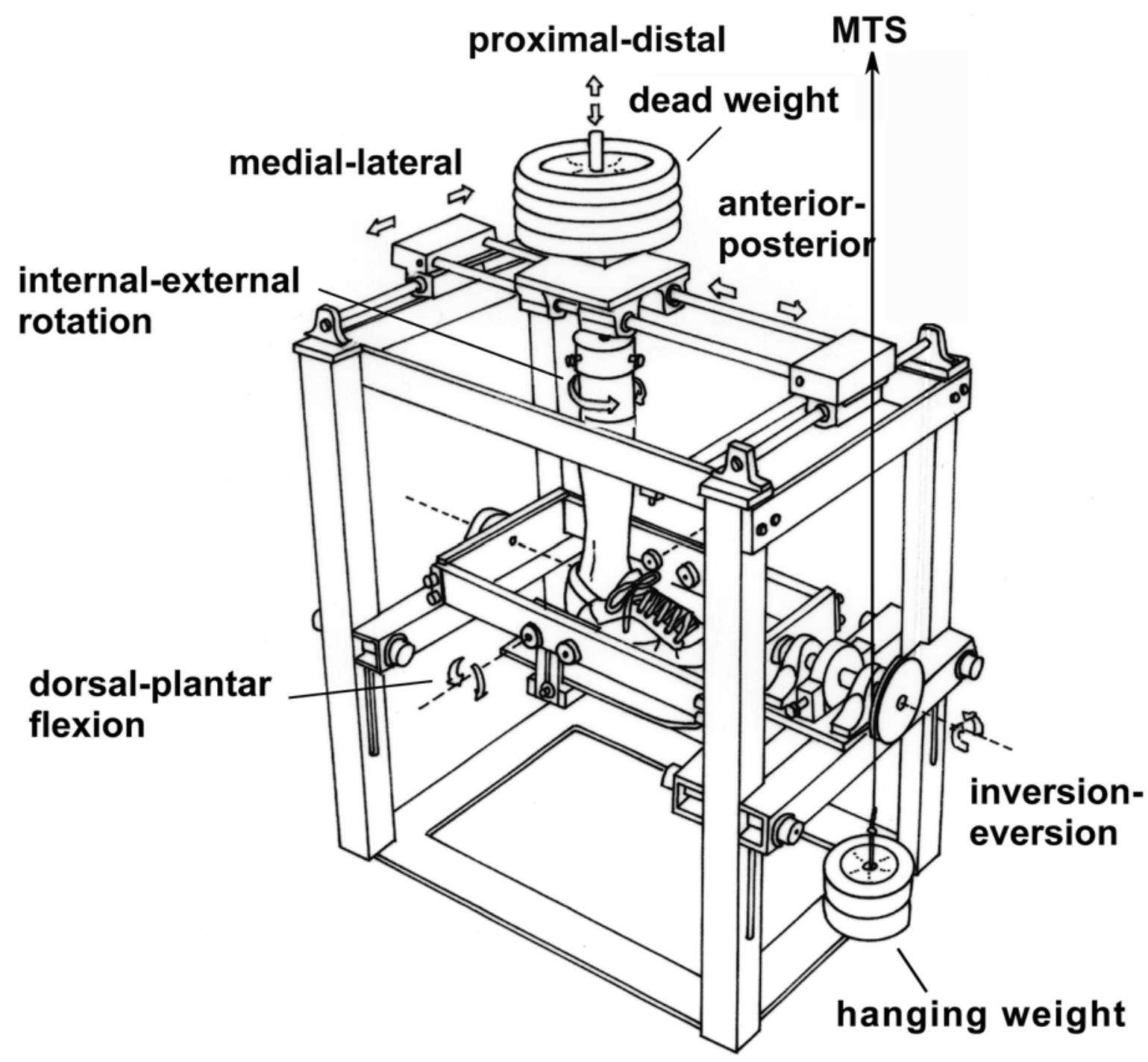

Fig. 1 Schematic of six degree-of-freedom testing apparatus 
a.

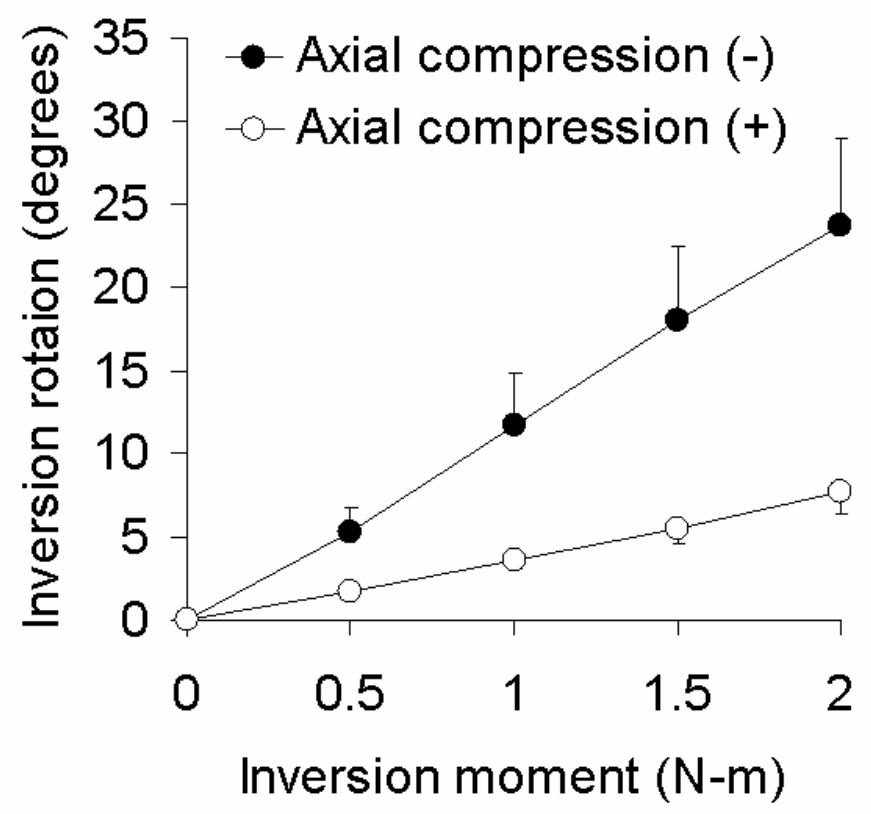

b.

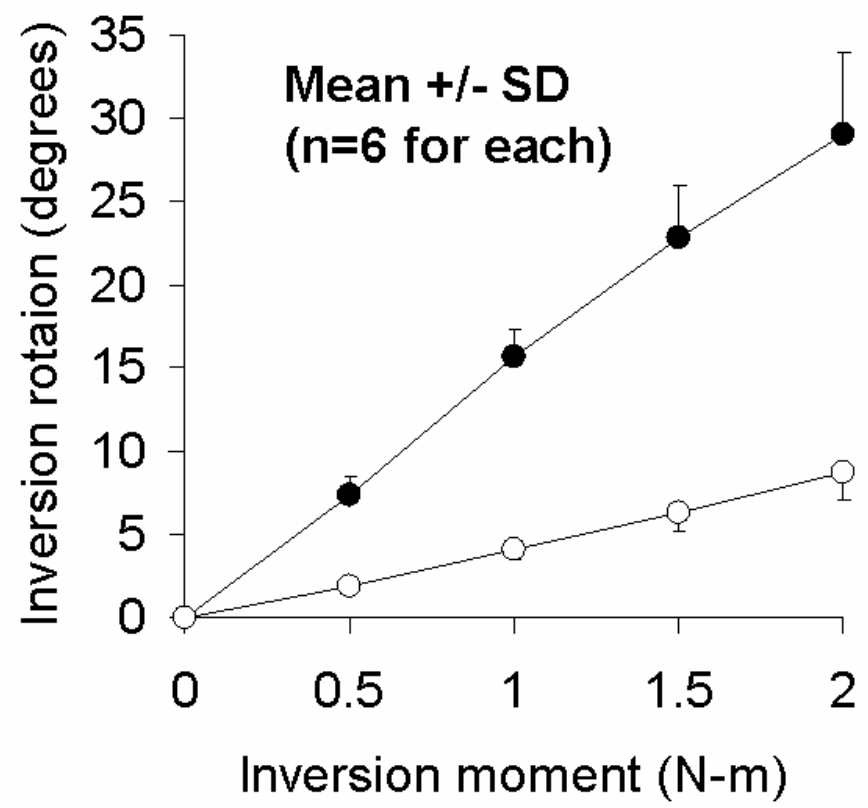

Fig. 2 Inversion moment versus inversion rotation for unbraced ankles with and without axial compression across the ankle in $0^{\circ}$ (a) and $20^{\circ}$ (b) of plantar flexion. A two-way ANOVA for the effects on the inversion rotation at inversion moment of $2.0 \mathrm{~N}-\mathrm{m}$ showed that there were significant effects of axial compression $(\mathrm{p}=0.0001$, power: $1-\beta=1.000)$, while no significant effect of plantar flexion was found ( $\mathrm{p}=0.0727$, power: $1-\beta=0.425)$. No significant interaction was found between axial compression and plantar flexion ( $\mathrm{p}=0.2160$, power: $1-\beta=0.218$ ). 
a.

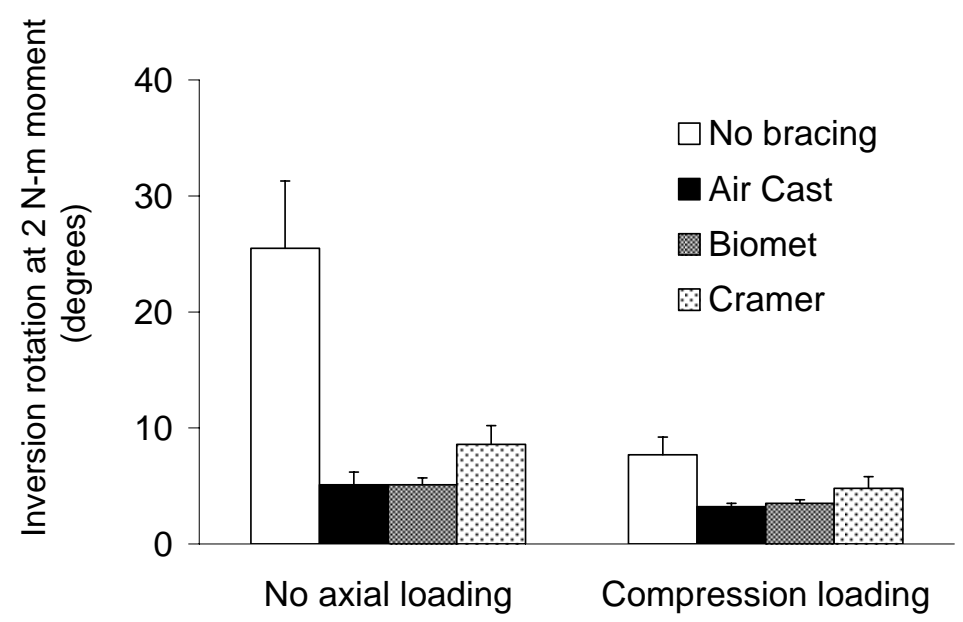

b.

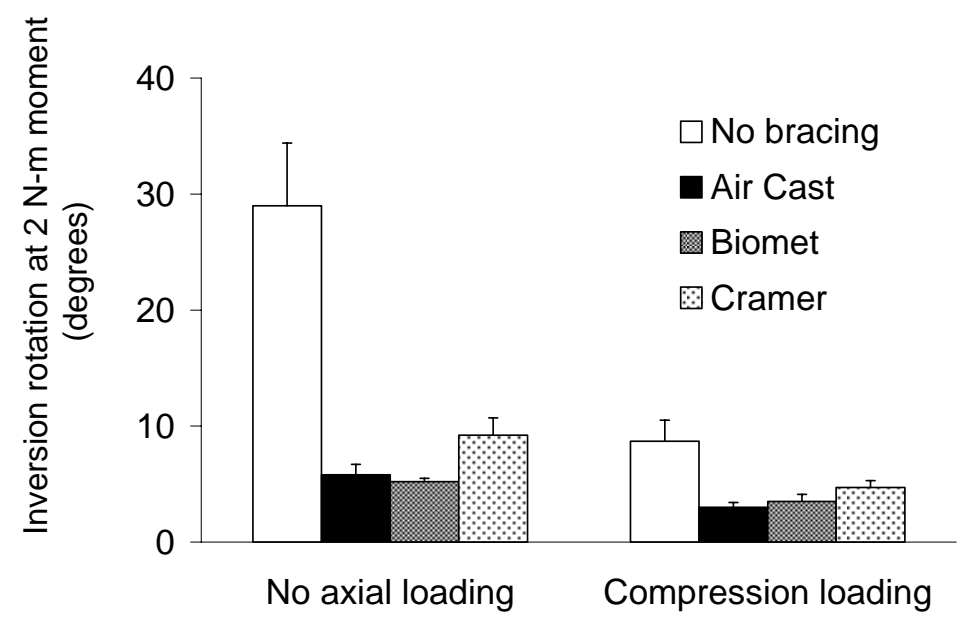

Fig. 3 Inversion rotation of the ankles after bracing with and without axial compression across the ankle in $0^{\circ}$ (a) and $20^{\circ}$ (b) of plantar flexion. Regardless of axial compression loading, all kinds of braces significantly reduced the inversion rotation of the ankle at inversion moment of $2.0 \mathrm{~N}-\mathrm{m}$ ( $\mathrm{p}=0.0001$ for each brace in $0^{\circ}$ and $20^{\circ}$ of plantar flexion). 
a.

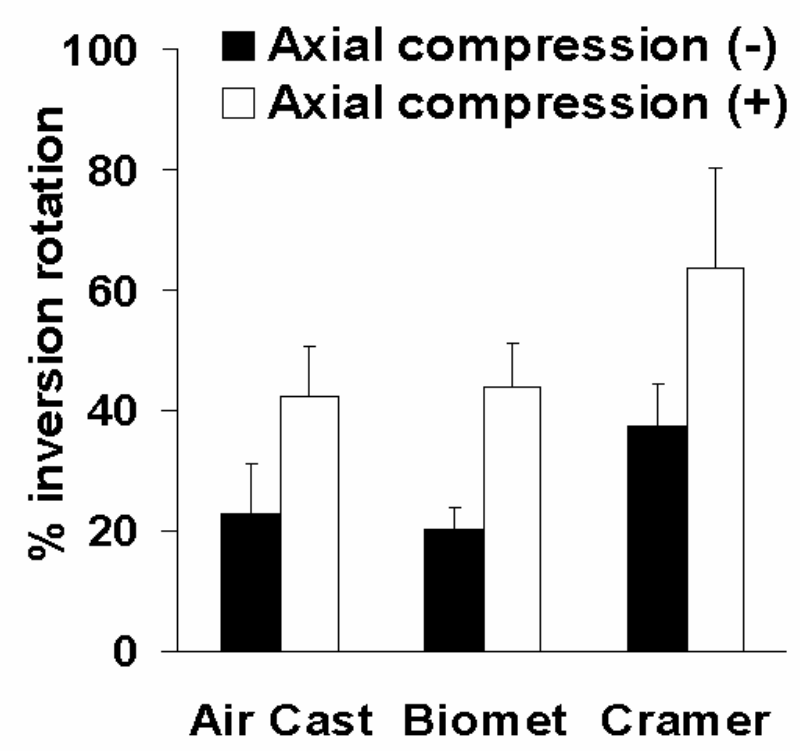

b.

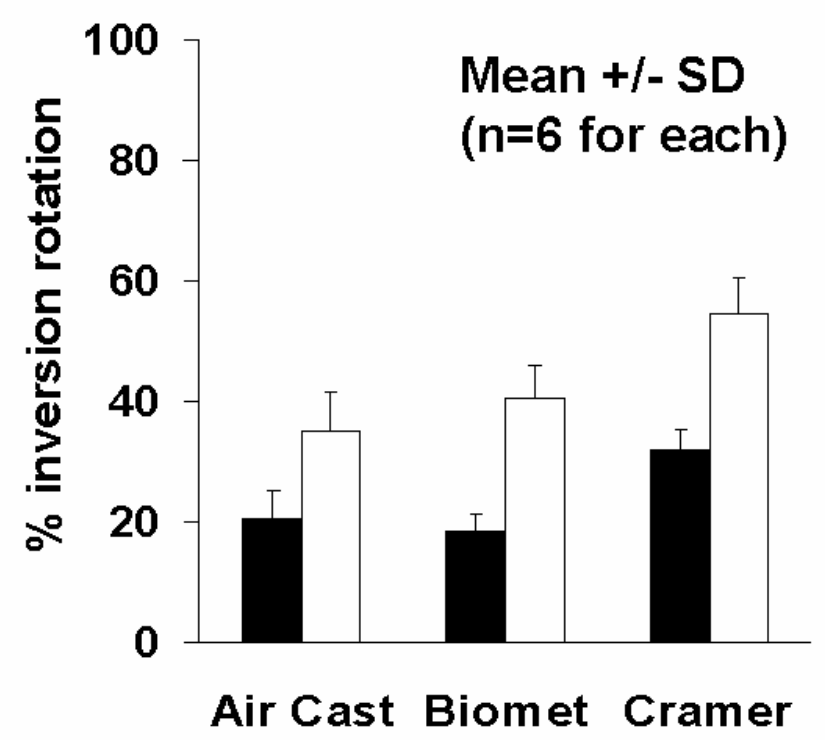

Fig. 4 Percent inversion rotation of the ankles after bracing with and without axial compression across the ankle in $0^{\circ}$ (a) and $20^{\circ}$ (b) of plantar flexion. Percent inversion means the relative rotation after bracing at inversion moment of $2.0 \mathrm{~N}-\mathrm{m}$ to that before bracing. A three-way ANOVA for the effects on \% inversion rotation showed that there were significant effects of axial compression ( $p=0.0001$, power: $1-\beta=1.000)$, type of brace $(p=0.0001$, power: 1 $\beta=1.000$ ), and plantar flexion ( $\mathrm{p}=0.0062$, power: $1-\beta=0.810$ ), while no significant interaction was found among three effects ( $p=0.8976$, power: $1-\beta=0.066)$. 